\title{
Appliance Electrical Consumption Modelling at Scale using Smart Meter Data
}

\author{
D.M. Murray ${ }^{\mathrm{a}, *}$, L. Stankovic ${ }^{\mathrm{a}}$, V. Stankovic ${ }^{\mathrm{a}}$, N.D. Espinoza-Orias ${ }^{\mathrm{b}}$ \\ ${ }^{a}$ Department of Electronic and Electrical Engineering, University of Strathclyde, 204 \\ George St., Glasgow, United Kingdom \\ ${ }^{b}$ Nestlé Research Center, Nestec S.A., Vers-Chez-Les-Blanc, 1000 Lausanne 26, Switzerland
}

\begin{abstract}
The food industry is one of the world's largest contributors to carbon emissions, due to energy consumption throughout the food life cycle. This paper is focused on the residential consumption phase of the food life cycle assessment (LCA), i.e., energy consumption during home cooking. Specifically, while much effort has been placed on improving appliance energy efficiency, appliance models used in various applications, including the food LCA, are not updated regularly. This process is hindered by the fact that the cooking appliance models are either very cumbersome, requiring knowledge of parameters which are difficult to obtain or dependent on manufacturers' data which do not always reflect variable cooking behaviour of the general public. This paper proposes a methodology for generating accurate appliance models from energy consumption data, obtained by smart meters that are becoming widely available worldwide, without detailed knowledge of additional parameters such as food being prepared, mass of food, etc. Furthermore, the proposed models, due to the nature of smart meter data, are built incorporating actual usage patterns reflecting specific cooking practice. We validate our results from large, geographically spread energy datasets and demonstrate, as a case study, the impact of up-to-date models in the consumption phase of food LCA.
\end{abstract}

\footnotetext{
* Corresponding author

Email addresses: david.murray@strath.ac.uk (D.M. Murray),

lina.stankovic@strath.ac.uk (L. Stankovic), vladimir.stankovic@strath.ac.uk

(V. Stankovic), NamyDaniela.EspinozaOrias@rdls.nestle.com (N.D. Espinoza-Orias)
}

Preprint submitted to Cleaner Production

March 15, 2018 
Keywords: Appliance modelling, Appliance usage, Energy savings, Life cycle assessment

\section{Introduction}

The food industry worldwide accounts for a significant fraction of carbon emissions. For example, in the United Kingdom (UK) alone, the food industry is responsible for about $14 \%$ of the energy consumption of the entire industry sector, equivalent to 7 million tonnes of carbon emissions per year [1]. The food Life Cycle Assessment (LCA) estimates material and energy input and output at all stages of the food product's life cycle - from acquisition of raw materials, production, processing, and packaging, to consumer use, and waste/recycling. For many food products, including ready meals, domestic cooking takes up a significant fraction of the total energy consumption of the product's LCA [2, [3], 44. Although the energy consumption of domestic cooking in developed countries has decreased by $31 \%$ from 1991 to 2008 [3], mainly due to improved energy efficiency of cooking appliances, cooking and beverage preparation in domestic settings still consume a substantial amount of energy, or approximately 7Mega Joule (MJ)/Kilogram (kg) [5, 6]. For example, according to [7, in the United States, domestic cooking accounts for 8-16\% (equivalent to $6.9 \times 10^{8}$ Giga Joule per year) of the total national annual energy consumption [8. Similarly, the report on Energy Consumption and Efficiency Trends in the European Union (EU) 9 estimates the energy consumption for ovens and hobs in private households in the EU-27 to be approximately 60 Tera-Watt hour (TWh) and states that for cooking appliances, there is still potential for energy savings. The situation is worse in many developing countries, where cooking consumes up to $90 \%$ of the overall residential energy consumption [10, 11, and it is mainly based on non-renewable energy.

Jungbluth [12] provides an early inventory of data for cooking at home using various appliances, so that food LCA studies can accurately quantify the food preparation stage. Sensitivity analysis of efficiency (ratio of energy input to 
energy output) shows that the type of vessels used, type of electrical appliance used (grill, oven, microwave oven, cast iron plate, induction stove), and the preparation method, have a large influence, resulting in the conclusion that there are large differences between efficiencies. Lakshmi et al. 13] tested different methods to cook rice in a microwave with different power levels, including the influence of soaking the rice prior to cooking. It was concluded that an electric rice-cooker is more energy efficient despite a longer cooking time compared to the microwave, but microwave cooking is as energy efficient as using a pressure cooker. A similar study on energy efficiency of cooking rice is presented in Das et al. [14, but only an electric rice cooker and a pressure cooker are tested.

Zufia and Arana [15] carried out the LCA of an industrially cooked dish, namely cooked tuna with tomato sauce, to assess the environmental impact of the production and distribution. However, the electricity consumed at home by a microwave for heating the ready meal is not considered. Calderón et al. [16] model the microwave consumption using its power rating, and focus on LCA of a canned ready meal, a stew product based on cooked pulses and pork meat cuts, highlighting subsystems with the highest environmental loads, concluding that $11 \%$ of the total energy consumption in the product life cycle is attributed to the domestic level. More recently, in [17, environmental burdens of the same dish at four production scales is considered, including canned food (reheated at home), the restaurant (cooked and heated in a traditional way and served), and the home-made dish with electricity consumption at household level estimated from electrical appliance specifications.

Oberascher et al. 18 highlight the variability of behaviour of consumers in using electrical appliances at the domestic level and provides empirical data on electricity consumption for a number of cooking processes, including heating water, baking potatoes and boiling eggs, concluding that the energy consumption of the microwave for heating water is lower than stove with a pot with and without a lid, but higher than kettle. Experiments conducted by Vattenfall [19] show that using the most energy efficient appliance in the kitchen for a specific cooking job is undoubtedly an effective way of lowering energy consumption. 
However, Fechner shows differences of up to $50 \%$ in energy consumption when six chefs all cooked the same meal with the same equipment (cited as per [20]), which agrees with the findings of DeMerchant 21]. Kemna 22] expects no further energy-saving potential possible for electric ovens from 2010 to 2020 from a purely technical design point of view; however, with a change to more sustainable consumer behaviour, the additional potential for energy savings is expected to be about $10 \%[22$.

The literature survey above demonstrates a clear need to capture the effect of different cooking styles, and consequently variable appliance usage, and explore the impact of the consumer phase, particularly at domestic level, in food LCA studies. This requires wider studies that can only be enabled via accurate and scalable models for computing the energy aspect of end-user cooking at home, and not relying on appliance manufacturer's specifications to estimate the consumption.

To this end, in 4, general models for quantifying energy consumption related to the food preparation in private households are proposed, including frying, boiling, oven roasting and microwave cooking. This is achieved via appliance load modelling, through exhaustive tests in laboratory conditions using different appliances and cooking settings. However, the models generated require a large number of variables to be known, such as type of food, its mass, the evaporation mass of food, which is not possible at scale. Similarly, the modelling of the combined oven in a restaurant setting, proposed recently in 23, also includes a large number of parameters which are not approachable at scale. Industrial scale applications already have a number of studies conducted, which model industrial versions of household appliances, such as modelling the cooking properties of industrial bread ovens 24. These, however, are very specific to the industry in question and therefore non transferable methodologies are applied.

This paper is inspired by some of the work done over a decade ago [4], and the appliance modelling performed, albeit in a different context, e.g., 25] where lines of best fit are applied for each setting of washing machines and [26] that use online survey, in-home study and laboratory experiments to assess the energy 
consumption of refrigerators. This paper proposes a methodology for generating general appliance models in a scalable manner to quantify energy consumption related to the usage of cooking appliances at domestic level. Specifically, our research hypothesis is that only smart meter data, comprising active power measurements with at least 60 second sampling in a similar format to the UK Smart Metering Equipment Technical Specifications v2(SMETS2) [27, is sufficient for building accurate major cooking appliance models. To prove our hypothesis, the paper draws upon load profiling, appliance mining and user activities assessment methodologies related to energy demand literature [28, 29]. For example, in [28, smart meter data is used to assess energy efficiency and sustainability of electric kettle usage. In 29], energy demand of different energy consuming domestic activities such as cooking and laundering is quantified. Load profiles of 11 major domestic appliances is studied in [30] showing that the majority of cooking load profiles are single state even when there may be large variation during the operation of the appliance.

While the proposed methodology is generic to all cooking appliances, in this paper, for ease of understanding, the methodology is illustrated on two electric cooking appliances with wide ownership in most countries, namely the electric oven and microwave. According to 31, almost $70 \%$ of households with ovens in England have electric ovens and just under $30 \%$ have gas ovens. Thus, in our study we chose to focus only on electrical appliances as they have a market dominance and the eventual move away from fossil fuels should increase the ownership of electrical appliances.

The appliance models proposed have a two-fold advantage over existing models: (i) models reflect current, more energy efficient and wider capacity appliances and (ii) models are not reliant on parameters that are difficult to estimate by non-specialists in large field studies. The proposed models are validated with existing literature, as well as on large electrical measurements datasets where electrical consumption of the two appliances in question was recorded. Furthermore, in order to demonstrate applicability and impact on food LCA, a case study is provided where figures for the microwave oven and electric oven are 
calculated for frozen ready meals and compared with recent LCA for the same food [32].

Note that smart meter data is now abundant for many countries allowing for many different applications such as non-intrusive load monitoring (NILM) (see [33] and [29] and references therein), consumption forecasting, demand response, load scheduling and energy saving feedback. Currently, there are many smart meter datasets openly accessible from different countries, providing domestic consumption patterns for geographically specific locations [34 37]. The proposed models can facilitate usage of these existing datasets to study sustainability in geographically spread households, e.g., by quantifying energy wastage and efficiencies due to different cooking appliances and practices.

The paper is organised as follows: Section 2 briefly reviews relevant appliance energy consumption models, Section 3 provides an overview of the proposed methodology and details of the field study carried out to build the appliance models, Section 4 describes the proposed models for oven and microwave, Section 5 shows the results of validating the proposed models on large-scale datasets and Section 7 presents a food LCA case study showing the viability of the proposed models. Section 8 concludes the work and highlights opportunities for future work.

\section{Existing Energy Consumption Models}

In this section, existing models for the microwave and electric oven are reviewed for quantifying energy consumption related to food preparation in the domestic sector. Both appliances have some functionality overlap, but use completely different heating methods.

The state-of-the-art microwave (MW) energy consumption model [4] requires knowledge of the food being cooked as well as water content, infeasible to collect at scale. It is given by:

$$
E_{M W}[M J]=\left(m_{\text {food }} \times T_{\text {elev }} \times c_{p}+\left(m_{\text {evap }} \times e_{e w}\right)\right) / e_{\text {totmw }}
$$


where the following parameters are required:

$$
\begin{aligned}
m_{\text {food }} & =\text { mass of product }(\text { in grams }[\mathrm{g}]) \\
t_{\text {elev }} & =\text { difference in food temperature }\left(\text { in Celsius degrees }\left[{ }^{\circ} \mathrm{C}\right]\right) \\
c_{p} & =\text { heat capacity of the food product }\left[M J /\left(g \times{ }^{\circ} \mathrm{C}\right)\right] \\
m_{\text {evap }} & =\text { mass of water evaporated }[\mathrm{g}] \\
e_{\text {ew }} & =2.26 \times 10^{-3}[\mathrm{MJ} / \mathrm{g} \text { water evaporated }] \\
e_{\text {totmw }} & =e_{\text {support }} \times e_{\text {trans }} \times e_{\text {magn }} \times e_{\text {mwcoup }} \\
e_{\text {support }} & =0.95(\text { efficiency for fan \& lamp \& controls }) \\
e_{\text {trans }} & =0.86(\text { efficiency for transformation }) \\
e_{\text {magn }} & =0.73(\text { efficiency for the magnetron }) \\
e_{\text {mwcoup }} & =0.57+3.8 \times 10^{-4} \times m_{\text {food }}\left(\text { for } 200<m_{\text {food }}<1000 \mathrm{~g}\right) \\
e_{\text {mwcoup }} & =0.95\left(\text { for } m_{\text {food }}>1000 \mathrm{~g}\right) .
\end{aligned}
$$

A similar microwave model is used in [13]. We note that other studies, briefly reviewed in Section 1, such as [18, 17, [16, 13, rely on heuristic measurements in laboratory conditions, or focus on preparation of particular dishes, or rely on power rating of the appliances and cooking recipes with the risky, and sometimes wrong assumption, that they will be followed.

The model for oven, validated in [4] using 23-59 litre ovens and data supplied by The Swedish Consumer Agency (http://www.konsumentverket.se) which had oven volumes ranging between 18-65 litres, is given by:

$$
\begin{aligned}
E_{O V E N}(M J) & =E_{h u} \times V \times T+E_{m t} \times V \times T \times t \\
& +E_{h p} \times m_{\text {tot }} \times \Delta T+2.26 \times 10^{-3} \times m_{\text {wevap }} \\
& +3.34 \times 10^{-4} \times m_{\text {frozen }} .
\end{aligned}
$$

The model requires the following input parameters: 


$$
\begin{aligned}
& E_{h u}=2.0 * 10^{-4} \\
& \text { Energy for heating one litre of oven volume. [(MJ/(litre } \left.\left.\left.\times{ }^{\circ} C\right)\right)\right] \\
& V=\text { volume of the oven in [litres] } \\
& T=\text { temperature the oven is heated to }\left(-20^{\circ} \mathrm{C} \text { start temp }\right)\left[{ }^{\circ} \mathrm{C}\right] \\
& E_{m t}=4.2 * 10^{-6} \\
& \text { Energy for maintaining a certain oven temperature in } \\
& \text { one litre for one minute }[M J /(\text { litre } \times \text { minutes })] \\
& t=\text { time for cooking (excluding preheating) [minutes] } \\
& m_{\text {tot }}=\text { mass of product }[\mathrm{g}] \\
& m_{\text {wevap }}=\text { mass of water evaporated }[\mathrm{g}] \\
& m_{\text {frozen }}=\text { mass of the product if frozen }[\mathrm{g}] \\
& e_{h p}=\text { heat capacity of the food product }\left[\mathrm{MJ} /\left(\operatorname{kg} \times{ }^{\circ} C\right)\right] .
\end{aligned}
$$

\section{Methodology}

Our aim is to provide models which can be easily applied to numerous existing smart meter energy datasets (see 35 for partial list) or used in large longitudinal consumer and energy studies, where information may be lacking with regards to specialised knowledge such as cooking settings, food temperature, appliance makes and models. Our research hypothesis is that by using only 
smart meter energy data we can build accurate models of major cooking appliances. To prove this hypothesis we first conducted a small field study to collect data for building mathematical energy consumption models, and then, validate the developed models using state-of-the-art models that use many parameters, difficult to collect in practice.

\begin{tabular}{|c|c|c|c|c|}
\hline Data & Data Pre- & Sionatul & Si & Appliance \\
\hline Acquisition & Processing & Detection & Validation & Modelling \\
\hline
\end{tabular}

Figure 1: Proposed methodology.

The methodology, from data acquisition to mathematical modelling, is summarised in Fig. 1. The input required is either total household energy consumption, which can be obtained directly from a household smart energy meter, or energy consumption of the appliance of interest, that can be measured using commercial plug meters [35]. Note that collected energy measurements are not readily usable for appliance modelling, requiring (1) Data pre-processing to filter out outliers, erroneous samples and noise, synchronise samples, and fill-in missing values; (2) Signature detection via edge detection or other NILM techniques 33. to isolate individual appliance power loads from the total household consumption (unless plug energy monitors are used at appliance level); (3) to acquire a relatively 'clean' or usable set of load signatures, signature validation is performed by using expert knowledge or an appliance database, to confirm that the signature belongs to a particular appliance of interest and remove signatures that were wrongly detected by NILM. The applied appliance modelling procedure is similar to that of [28].

\subsection{Data Acquisition}

Electrical consumption data for building the proposed appliance models, was collected during a field trial. Four households were recruited and monitored using a combination of Raspberry Pi (https://www.raspberrypi.org/) and the off-the-shelf Smappee (http://www.smappee.com/uk/home) real-time energy monitor. Measurements were taken at 1 second intervals, for up to 120 
days. At the beginning of the study, all four households filled an Appliance Usage Survey containing information about appliance ownership and general patterns of appliance usage, again for the purposes of signature validation. The survey confirmed that all houses owned a microwave and all but one was likely to use it daily; ovens are most likely to be used in the afternoon and evenings.

In addition, for the purposes of validation, time diaries were also kept by household participants, including recording the start time of each appliance use along with settings of the appliance in use. Recorded start times in time diaries are in general accurate to around 1-2 minutes of the actual usage time. It was found that the recording of the recipe or type of food prepared using an electrical appliance did not affect the energy consumption in a significant way and thus did not affect the appliance consumption models.

\subsection{Data Pre-processing}

The first step is making sure the measurements are suitable for use by filtering out outliers and erroneous measurements, including spikes, following a similar methodology to 35.

The second step is synchronisation of readings. Raw data generally does not have a uniform sampling rate and therefore isolating appliance signatures becomes more complex when varying time frequencies are involved. Re-sampling timestamped data to one second intervals helps to achieve this uniformity; each sample is rounded to the nearest second (in this case removing the millisecond component). Once this is completed, forward filling using a previous sample fills any gaps which have arisen. Forward filling however should be limited (in our case we chose 2 seconds) to avoid skewing electrical signatures. These methods are generic regardless of the data source.

\subsection{Signature Detection and Validation}

Smart meters measure only the household's total energy consumption. To use smart meter data for appliance load modelling, it is necessary to isolate 
appliance usage, which is commonly done via NILM [33. For this study, we develop a simple, supervised, edge-detection based method given in Algorithm 1 .

The input to the algorithm are smart meter active power readings collected at time $t$, pow $_{t}$ in Watts $(\mathrm{W})$, which are used to calculate edges, as $\Delta$ pow $_{t}=$ pow $_{t}-$ pow $_{t-1}$, defined as difference in power value between sequential timestamps. An edge could be either a rising or a falling edge: a RisingEdge is a positive change in power (e.g., when an appliance is switched on or goes to a high consuming state) and a FallingEdge is a negative change in power (e.g., an appliance going to a low consuming state or is switched off).

The appliance metadata are data gathered from time diaries and individual appliance monitoring (IAM); these include instantaneous maximum and minimum observed power draw for the appliance of interest $\left(\right.$ pow $_{\min }$ and pow $_{\max }$ ) and time durations $\left(d u r_{\min }\right.$ and $\left.d u r_{\max }\right)$, and the number of states. Since the power draw of the appliances of interest oscillates between high power state (e.g., heating state) and low power state (maintaining the heat), to avoid picking up low power state as switching off the appliance (that is, as a FallingEdge), we also estimate switching_time as the time between an appliance going to a low power state (where it may appear to be off) before returning to a high powered state.

After all candidate RisingEdge and FallingEdge are detected, each RisingEdge is matched with the closest in time FallingEdge if the time duration between these two edges is within the acceptable limits, that is, between $d u r_{\text {min }}$ and $d u r_{\text {max }}$, minimum and maximum appliance operation time duration observed from the Appliance metadata. Next, by comparing the time difference between the rising and falling edges with switching_time, a check is performed to ensure that the FallingEdge is not due to appliance transiting to a low power state. 


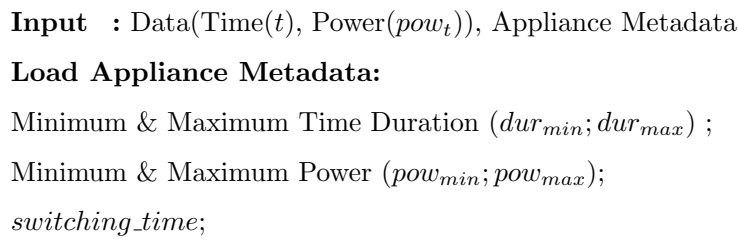

Algorithm 1: Signature Detection Pseudocode. The MatLab code is available at https://github.com/David-Murray/MatLab-Appliance_ 
The proposed edge detection algorithm is limited by multiple simultaneous appliance uses and appliances with similar-valued consumption and duration. More sophisticated NILM methods can be used to provide higher disaggregation accuracy [33, 34, 38.

Algorithm 1 is run for each appliance of interest separately, and it returns the time duration and energy consumption of each detected appliance-of-interest use. To ensure that none of these detected uses comes from another appliance with similar load, or with multiple appliances being switched on/off at the same time, for each paired output Rising/Falling edge, we perform check with time diary or IAM measurements, if available, or validate it against known appliance signatures, e.g., [39, to check if they fall within a valid range of values (e.g., similar consumption, duration, time of day). This is done to ensure that incorrectly disaggregated signatures are not used for the modelling stage.

All correct, labelled appliance signatures, namely the duration $t_{\text {secs }}[\mathrm{sec}]$ and energy consumption $\left(E_{a p p}[M J]\right)$ per use, are then fed to the Appliance Modelling stage in Section 4 where app refers to the appliance being modelled, e.g., MW for microwave.

\section{Appliance Modelling}

In this section, we perform curve fitting on the processed and cleaned energy measurements, namely time duration and energy consumption, to construct generalised models of appliance consumption based only on information gathered from smart energy meters as described in Section 3 and are widely available in numerous existing smart meter datasets that have been made public (see Table 1 in [35]). Note that other parameters such as temperature, food weight etc., which are difficult to gather during a large-scale longitudinal energy and consumer studies, are excluded. Resulting mathematical models for the microwave and the oven are presented next. 


\subsection{Microwave Consumption Model}

The microwave's power consumption over time is pulsed as microwaves are typically run at either $100 \%$ power, or variations on this at $20 \%$ intervals $(20,40$, $60,80 \%)$. To develop a model, the time duration $\left(t_{\text {secs }}\right)$ and energy consumption $\left(E_{M W}\right)$ values were obtained using the Signature Detection algorithm (i.e., Algorithm 1) as explained in Section 3.3. The other two parameters used in the model are: power $_{\text {watts }}$, that is, the rated magnetron power of the microwave, obtained from the appliance manual or information labels of the respective microwaves, which is fixed for each microwave; and setting percentage, which denotes the power setting of the microwave (e.g., $60 \%$ of power $_{\text {watts }}$ ), as set by the consumer per run and, for the purpose of model development, was obtained from time diaries.

Following curve fitting on the output of Section 3.3 , which isolated 584 valid microwave signatures, the following mathematical linear model for the consumed energy is obtained:

$$
E_{M W}(M J)=\left(0.0010899 \times t_{\text {secs }}\right)+\left(\text { power }_{\text {watts }} \times 5.8681 \times 10^{-6}\right) .
$$

It should be noted that the above microwave model is limited by the availability of consumption data, and thus it is inadvertently biased towards the tested microwaves, which ranged between $700 \mathrm{~W}$ and $900 \mathrm{~W}$. Reduced power band settings, e.g., $80 \%$ of $700 \mathrm{~W}(560 \mathrm{~W})$, will be estimated well while, $60 \%$ of $700 \mathrm{~W}$ will be over estimated. To reduce errors of predicting lower powered microwaves and, as such give a better overall range, $700 \mathrm{~W}$ uses were weighted appropriately to help improve model predictions. This resulted in a more accurate quadratic microwave model, given in equation below: 


$$
\begin{aligned}
E_{M W}(M J)^{\text {Quadratic }} & =\left(0.0015893 \times \text { power }_{\text {watts }}\right) \\
& +\left(-1.4823 \times \text { setting }_{\text {percentage }}\right) \\
& +\left(0.0001032 \times t_{\text {secs }}\right) \\
& +\left(0.0020663 \times\left(\text { power }_{\text {watts }} \times \text { setting }_{\text {percentage }}\right)\right) \\
& +\left(-9.9386 e-08 \times\left(\text { power }_{\text {watts }} \times t_{\text {secs }}\right)\right) \\
& +\left(0.0012324 \times\left(\text { setting }_{\text {percentage }} \times t_{\text {secs }}\right)\right) \\
& +\left(-2.237 e-06 \times\left(\text { power }_{\text {watts }}^{2}\right)\right) \\
& +\left(0.018915 \times\left(\text { setting }_{\text {percentage }}^{2}\right)\right) \\
& +\left(-5.1134 e-07 \times\left(t_{\text {secs }}^{2}\right)\right)
\end{aligned}
$$

Compared to the previous linear model, this quadratic model incorporates

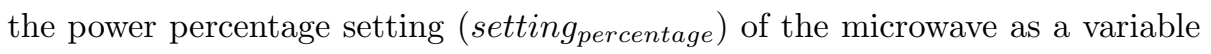
(e.g., 60\%, 80\%). Note that, in contrast to previous models (see Section 2), our model predicts the amount of consumed energy $E_{M W}$ based purely on the duration $t_{\text {secs }}$, power rating power $_{\text {Watts }}$ (which is a fixed parameter for each

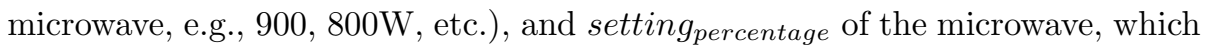
can be easily recorded. Alternatively, the model can predict microwave setting, based on the measured $E_{M W}$ and $t_{\text {secs }}$, that is, purely from the Algorithm $1 \mathrm{~s}$ output.

We first validate our proposed model visually by comparing the predicted energy consumption values from the model with actual energy consumption values, as shown in Figure 2. Six distinct power settings were used in the time diaries gathered, resulting in power $_{\text {watts }} \times$ setting $_{\text {percentage }}$ consumption bands of $900 \mathrm{~W}, 800 \mathrm{~W}, 700 \mathrm{~W}, 560 \mathrm{~W}, 420 \mathrm{~W}$, and $280 \mathrm{~W}$ of which, there were 28,6 , 148, 185, 208, 9 uses, respectively. The normalised root mean squared error (NRMSE), calculated using Eq(7), for these 6 settings is 0.44, 0.15, 0.002, 0.04, 0.05 , and 0.04 , respectively.

It can be seen from Figure 2, that the Predictions from the quadratic model show a very good fit with the actual measurements for all power settings, includ- 
ing the $900 \mathrm{~W}$ setting that shows the highest NRMSE. Therefore, we conclude that the NRMSE between actual measurements and predicted values from the model of the microwave of around 0.5 is acceptable.

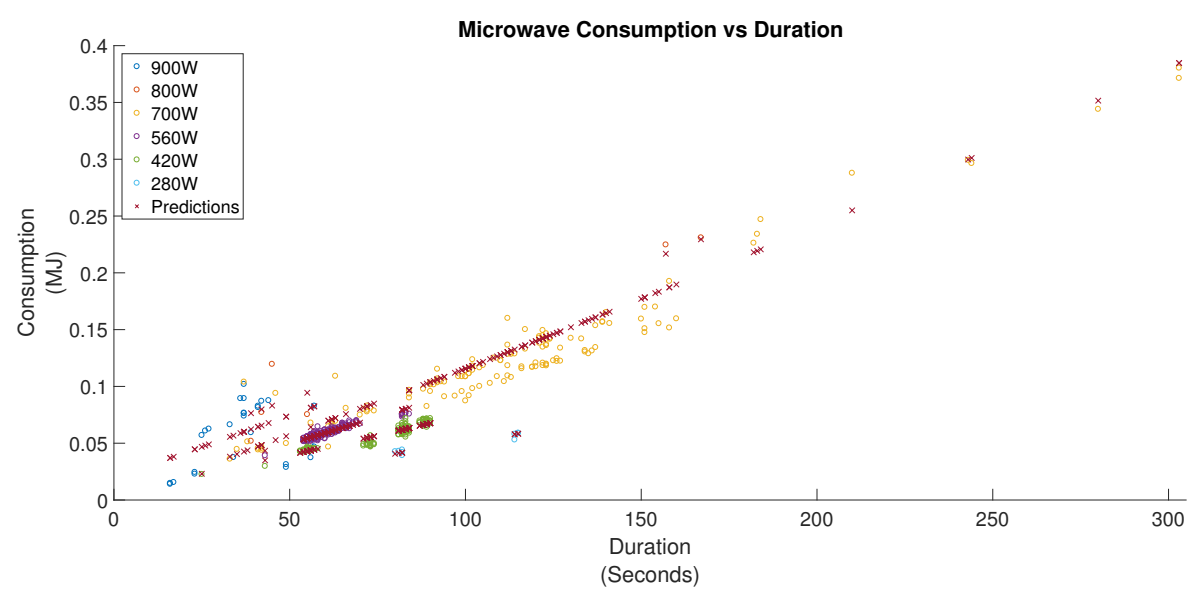

Figure 2: Detected microwave consumptions and predicted values using the proposed quadratic model Eq. 4

Furthermore, Table 1 shows how our model output compares to that of the state of the art 4, described in Section 2. As in 4, the ratio, measured as the predicted energy usage from the model divided by the measured energy usage, is used for assessing the accuracy, i.e., the results closer to 1 indicate better prediction. The better performing method is highlighted in green.

\begin{tabular}{cccccccccc} 
Microwave Power & Duration (mins/secs) & Son. Model Prediction & Our Model & Our Model (Quad) & Son. Measured & Ratio Son. & Ratio Our & Ratio Our (Quad) \\
\hline 750 & $3 / 5$ & 0.23 & 0.21 & 0.23 & 0.22 & 1.05 & 0.95 & 1.09 \\
750 & $3 / 5$ & 0.20 & 0.21 & 0.23 & 0.22 & 0.91 & 0.95 & 1.09 \\
800 & $2 / 53$ & 0.25 & 0.19 & 0.23 & 0.22 & 1.14 & 0.86 & 1.05 \\
700 & $3 / 18$ & 0.25 & 0.22 & 0.23 & 0.22 & 1.14 & 1 & 1.05 \\
750 & $4 / 30$ & 0.37 & 0.30 & 0.32 & 0.32 & 1.16 & 0.94 & 1.00 \\
750 & $4 / 30$ & 0.28 & 0.30 & 0.32 & 0.32 & 0.88 & 0.94 & 1.00 \\
800 & $3 / 0$ & 0.28 & 0.20 & 0.23 & 0.22 & 1.27 & 0.90 & 1.09 \\
700 & $4 / 0$ & 0.28 & 0.27 & 0.27 & 0.25 & 1.12 & 1.08 & 1.08
\end{tabular}

Table 1: Comparison of the model prediction of Sonesson [4] (abbreviated to Son.) and our proposed linear Eq. 3 \& quadratic model Eq. 4 using the values recorded by 4 given in [MJ].

We can see that the proposed quadratic model is more accurate than the proposed linear model and benchmark model of [4]. This confirms that knowl- 
edge of the food being prepared does not impact the consumption phase of the microwave in a significant manner.

In [16, it claimed that an $800 \mathrm{~W}$ rated microwave at $100 \%$ for approx 8 minutes consumes $0.1 \mathrm{kWh}(0.36 \mathrm{MJ})$. Using our linear model the same microwave would be expected to consume $0.1394 \mathrm{kWh}(0.5 \mathrm{MJ})$, and our quadratic model would be consuming $0.1919 \mathrm{kWh}(0.69 \mathrm{MJ})$.

\subsection{Oven Consumption Model}

Oven-baking is still one of the most used cooking practices in Europe, with electric ovens present in most homes [4, 23]. The oven operates in two stages: (i) preheating/restoring heat, when the oven typically draws a constant power load, and (ii) maintaining heat. The set temperature, type and amount of food being baked, affects only the time the oven will be in each of the two states. Within this section, to build a model, the time duration $\left(t_{\text {secs }}\right)$ and energy consumption $\left(E_{\text {Oven }}\right)$ were obtained from the edge detection algorithm (i.e., Algorithm 1) as described in Section 3.3 the set temperature $\left(\right.$ temp $\left._{\text {Oven }}\right)$ of the oven has been obtained from time diaries, or if this is not available, estimated based on the initial preheating duration, which is close to linear for each oven.

Most cooking recipes require the oven to be pre-heated to a set temperature. During this phase, the oven door is usually kept shut meaning that the time to reach temperature will be linear with the assumption that the oven is in good working order and condition. The cooking phase may consist of door openings as food is introduced and later checked or taken out. When the door is opened the oven will lose temperature and require another heating stage to return to the set temperature. Different oven settings produce different signatures; however, they still retain the general heating/maintenance cycle with adjusted timings. In our models we assume that the door is not opened frequently or unnecessarily and that only one dish is added for the cooking stage. Note that the model is limited by the available oven data, that is, we expect that the model will not accurately represent very large ( $\geq 80$ litres) or very small ovens ( $\leq 50$ litres).

In developing a scalable model for the oven load, we start from the Sonesson 
model given by Eq. 2 and attempt to remove dependency of the model on parameters that are difficult to acquire.

First, using the data collected from smart meters (see Subsection 3.1) we estimate two static parameters of Eq. (2) - $E_{h u}$ and $E_{m t}$. As the values reported in [4] were set back in 2003, our obtained estimates differ from Eq.22) due to the newer and more energy efficient oven designs. This situation further motivates our proposal for appliance modelling methodologies that can be updated regularly, without significant effort and cost.

In our field study, the 58-litre oven is the oldest and worst performing from an energy point of view. The average energy values given by Eq. (2) for $V=58$ litre oven, for energy needed for heating and maintaining the heat, respectively, are $E_{h u}=2.0 \times 10^{-4}\left[M J /\left(\right.\right.$ litre $\left.\left.\times{ }^{o} C\right)\right]$ and $E_{m t}=4.3 \times 10^{-6}[M J /($ litre $\times$ minutes $)]$. Our experiments show that this value should be lowered to around $1.1055 \times 10^{-4}\left[\mathrm{MJ} /\left(\right.\right.$ litre $\left.\left.\times{ }^{\circ} \mathrm{C}\right)\right]$ for $E_{h u}$. Our recommendation is to increase slightly the $E_{m t}$ value from Eq.(2) to $1.7288 \times 10^{-5}[M J /($ litre $\times$ minutes $)]$ due to the increase in the size of oven cavities. Table 2 summarises the mean and variance of the values obtained from our models from the detailed field study of two ovens, where the combined average is the recommended value for $E_{h u}$ and $E_{m t}$.

\begin{tabular}{lcccc}
\multirow{2}{*}{ Volume (Litre) } & \multicolumn{2}{c}{$E_{h u}$} & \multicolumn{2}{c}{$E_{m t}$} \\
& Mean & Variance & Mean & Variance \\
\hline 58 & $1.2905 \times 10^{-04}$ & $1.6243 \times 10^{-10}$ & $2.1575 \times 10^{-05}$ & $2.3426 \times 10^{-11}$ \\
74 & $8.0806 \times 10^{-05}$ & $1.6753 \times 10^{-10}$ & $1.0398 \times 10^{-05}$ & $1.0288 \times 10^{-11}$ \\
Combined Avg. & $1.1055 \times 10^{-04}$ & & $1.7288 \times 10^{-05}$ &
\end{tabular}

Table 2: Experimentally obtained values for the energy needed for heating and maintaining the heat, for the two ovens in the study.

Table 2 is an update to the model of 4 described in Section 2 , however the large number of variables that need to be known hamper using the model 
in large-scale studies. Instead, we propose the following scalable model, if the oven volume is unknown:

$$
E_{\text {Oven }}[M J]=\left(0.0037372 \times \operatorname{temp}_{\text {Oven }}\left[{ }^{o} C\right]\right)+\left(0.0011084 \times t_{\text {secs }}[s]\right) .
$$

The difference in the volume of the oven causes variations resulting in an NRMSE between predicted and actual values of 0.25 , as calculated by Eq.(7). We conclude that volume is important for estimating power consumption, especially with the current large variation in oven volumes on the market. A revised model that incorporates time duration, set temperature and oven volume is given by the following equation:

$$
\begin{aligned}
E_{\text {Oven }}[M J]= & \\
& (-0.064859 \times V[\text { Litre }]) \\
& +\left(0.028626 \times \text { temp }_{\text {Oven }}\left[{ }^{\circ} \mathrm{C}\right]\right) \\
& +\left(0.00094777 \times t_{\text {secs }}[\text { sec }]\right) .
\end{aligned}
$$

With the addition of the Volume $(V)$ component, Eq. (6) has a reduced NRMSE of 0.19 when compared to Eq.(5). Fig. 3 shows the validation results for the energy consumption vs. operation time for the two ovens, this time showing a much better agreement between the predicted values from the revised model from Eq.(6) and the actual measured values. Therefore, we define an acceptable value for NRMSE between actual measurements and predicted values from the model of the oven to be around 0.3 . 


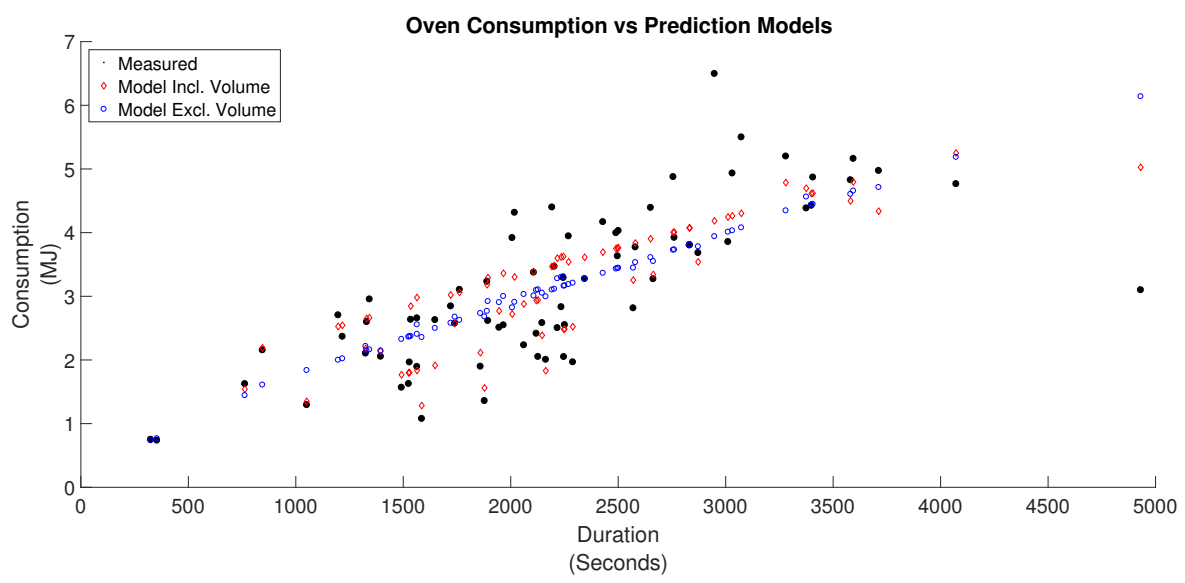

Figure 3: Oven Total Energy Consumption against time: actual (black circles) vs. Predicted (red diamond \& blue circle).

\section{Model validation using publicly available datasets}

To further validate our models at scale and investigate the effect of variability of consumer behaviour, as reported in Oberascher et al. [18, on the proposed appliance models, we use data from several publicly available datasets, including: (a) REFIT dataset [35, that comprises aggregate readings and individual appliance power consumption from 20 UK households taken over a period of 2 years where householders were going about their normal day-to-day routines under no test conditions; (b) eco dataset from Switzerland [36]; (c) REDD dataset from the United States [40]. The datasets were chosen to validate against geographic variability in appliance type ownership and patterns of use, and experiments were conducted over hundreds of uses for statistical accuracy.

We use NRMSE as a measure of the error. NRMSE was chosen as large errors are more heavily weighted than Mean Absolute Error (MAE); this is desirable, as a lower NRMSE shows that the model is less prone to inaccurate estimations and therefore when performing LCA or yearly consumption estimates the model is proven to be a reliable guide. The NRMSE captures the error in the models predicted consumption against the actual measured consumption, and 
was calculated as:

$$
N R M S E=\frac{1}{\frac{1}{N} \sum_{i=1}^{N} E_{\text {app }_{\text {measured }_{i}}}} \sqrt{\frac{\sum_{i=1}^{N}\left(E_{\text {app }_{\text {model }}}-E_{\text {app }_{\text {measured }}}\right)^{2}}{N}}
$$

where $E_{\text {app }_{\text {model }_{i}}}$ and $E_{\text {app }_{\text {measured }_{i}}}$ denote the energy consumption estimated by the model and measured, during the $i$-th use, respectively, of the appliance in question (microwave or oven), and $N$ is the number of appliance uses detected in the dataset.

\subsection{Microwave}

Table 3 shows the NRMSE results for microwave from the REFIT dataset where microwave model, i.e., its power rating, is known. Note that, in the REFIT dataset, the readings were collected at 6-8 sec interval. At the time of the REFIT study, the measurements were made with a less accurate electricity meter than the one used to build our model, and this resulted in higher acquisition noise and synchronization issues. Out of 20 households monitored, the make and model number of 7 microwaves were collected during the REFIT study, which means that the output power, i.e., power $_{\text {watt }}$, for these seven microwaves was known. Table 4 shows the equivalent results for eco and REDD datasets, where the make and model of the microwaves are unknown.

The small NRMSE values for all microwaves in both Tables 3 and 4 (below the acceptable boundary of 0.5 ) confirm that the proposed microwave model of Eq. (4) accurately estimates the energy consumption without any knowledge about the type of food being cooked or the food temperature, and also that the proposed model is accurate even with variable consumer behaviour across different households and countries. NRMSE was only large for Houses 9 and 17 due to high level of noise in the dataset and many loads running in parallel. 


\begin{tabular}{lccr} 
REFIT House & Known Power $[\mathrm{W}]$ & Uses & NRMSE \\
\hline House 3 & 1000 & 611 & 0.28 \\
House 4 & 700 & 1395 & 0.35 \\
House 5 & 1000 & 2442 & 0.47 \\
House 8 & 1000 & 1429 & 0.27 \\
House 9 & 700 & 146 & 0.53 \\
House 17 & 850 & 715 & 0.55 \\
House 20 & 800 & 755 & 0.36
\end{tabular}

Table 3: Model (Eq. 4 NRMSE when predicted for 7 microwaves from the REFIT dataset, where output power is known. House numbers correspond to the numbers in the REFIT dataset. Known Power refers to the known power rating of the microwave, i.e., power $_{\text {watt }}$ is known.

\begin{tabular}{lccr} 
House & Estimated Power [W] & Uses & NRMSE \\
\hline REDD-H1 & 700 & 278 & 0.25 \\
REDD-H2 & 900 & 46 & 0.34 \\
REDD-H3 & 900 & 46 & 0.27 \\
ECO-H4 & 700 & 812 & 0.31 \\
ECO-H5 & 700 & 59 & 0.33
\end{tabular}

Table 4: Model (Eq. 4) NRMSE when predicted for microwaves from eco and REDD datasets. House numbers correspond to the numbers in the REDD and Eco datasets. Estimated Power refers to the guessed power rating of the appliance, i.e., powerwatt is assumed based on the measurements. 


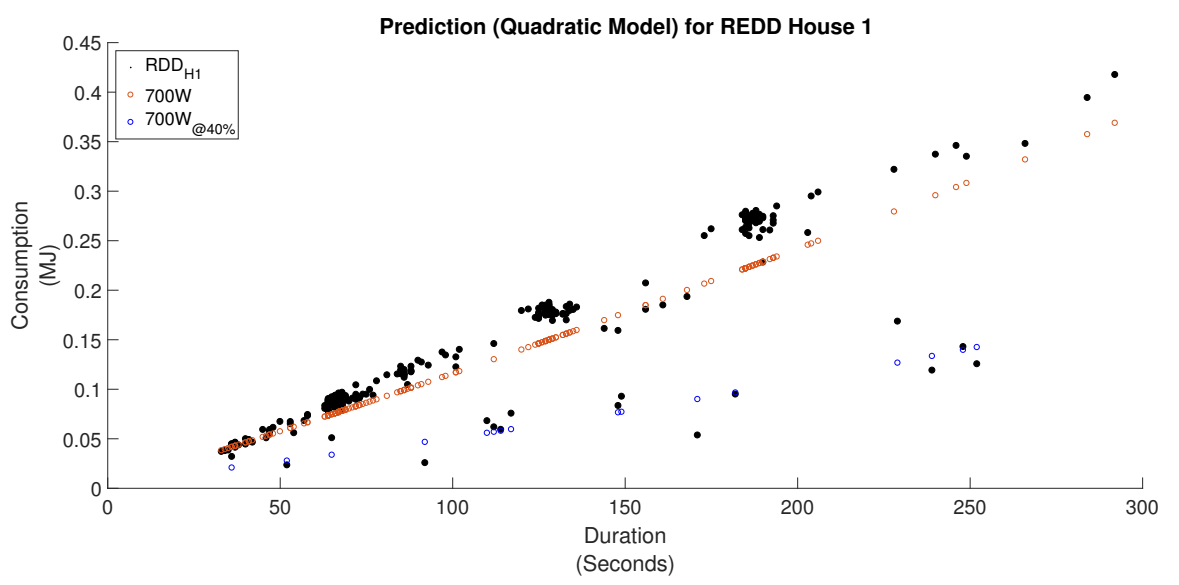

Figure 4: Prediction of microwave from REDD House 1, where power ${ }_{W a t t s}$ and

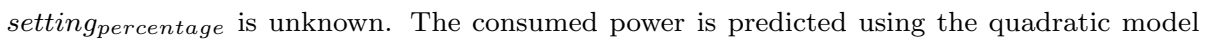
Eq. 44. The actual readings are denoted by $\mathrm{RDD}_{H 1}$.

Fig. 4 shows energy consumption vs. duration for REDD House 1 - measured values (in black) and predicted consumption using the proposed quadratic model (Eq. 4). It can be seen that the model estimates the load measurements accurately, despite the fact that power rating power $_{\text {watt }}$ is unknown. Assuming a $700 \mathrm{~W}$ power setting (taken from Table 4 ) at $100 \%$ and $40 \%(280 \mathrm{~W}$ ) the NRMSE for the house drops from 0.25 to 0.17 .

\subsection{Oven}

The proposed oven model is validated using the REDD dataset, which includes an oven monitored at plug level (no disaggregation needed) and the REFIT dataset, where oven uses were extracted from the aggregate data using the methodology described in Section 3.3 . Fig. 5 shows the energy consumption vs. time duration, for House 1 from the REDD dataset and Houses 1 and 10 from the REFIT dataset. Oven make and model for both datasets are unknown, as is the target temperature. Consumption measurements obtained from three ovens with 53 uses using the aforementioned datasets are plotted using red markers. The proposed model, Eq. (6), showing prediction consumption values, is plotted for the following parameters: volumes (Litre) of 56,65, and 74, and target 
temperatures of $160^{\circ} \mathrm{C}$ and $180^{\circ} \mathrm{C}$.

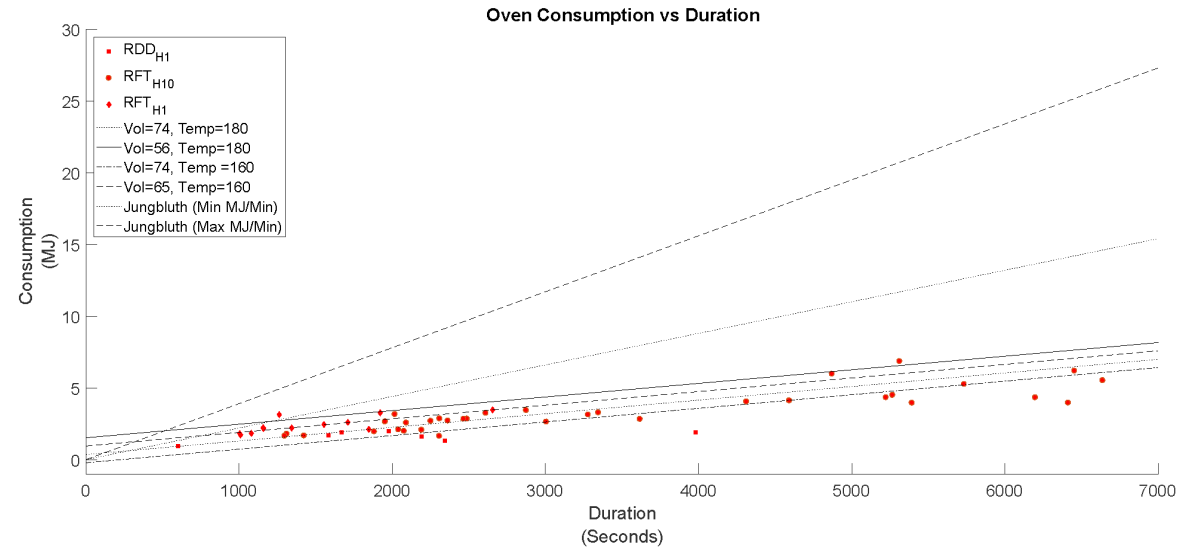

Figure 5: Oven predictions using the proposed model and reference model 12 for House 1 from REDD (RDD) dataset and Houses 1 and 10 from REFIT (RFT) dataset.

It can be observed that the actual measurements $\left(R D D_{H 1}, R F T_{H 10}, R F T_{H 1}\right)$ fall within the predicted consumption using our model for four different oven volume and temperature combinations (where values are specified by Vol for Volume given in Litres and Temp for Temperature given in $\left.{ }^{\circ} \mathrm{C}\right)$. Visually Fig. 5 confirms that the models are accurate and that knowledge of the type of food being prepared does not impact on the accuracy of the model. The model is especially accurate when the duration is up to 45 mins. A lower accuracy of the model for durations greater than an hour is probably due to a lower temperature setting used, or the oven door being opened too many times, resulting in an NRMSE of $0.2868,0.5208,0.3260$, and 0.2873 , for the four cases shown in Fig. 5 respectively, because the temperature and volume for the oven measurements are unknown so cannot be matched to each usage scenario. We also show how the actual measurements compare with those predicted by the reference model of 12 from 1997, shown as dotted lines in Fig. 5. As expected, the latter model (Jungbluth) overestimates the actual consumption, predicting it in the range $0.132 \mathrm{MJ} / \mathrm{min}$ to $0.234 \mathrm{MJ} / \mathrm{min}$. We can conclude that ovens now come with better efficiencies and that models need to be updated regularly to reflect 
contemporary ownership.

\section{Limitations of the study and threats to the validity of results}

In this section, we summarise two limitations of the proposed models, namely detection of appliance signatures from the smart meter aggregate load introduced in Section 3.3, and availability of appliance models used for model generation in Sections 4.1 and 4.2

Algorithm 1, proposed in Section 3.3. uses edge detection to isolate usages of appliances of interest (i.e., oven and microwave). The edge detection algorithm is limited by multiple simultaneous appliance uses and appliances with similarvalued consumption and duration. Appliance uses in these circumstances are excluded from modelling due to uncertainty. More sophisticated NILM methods can be used to provide higher disaggregation accuracy [33, 34, 38]. Alternatively, individual appliance power measurement sensors can be used to directly measure power consumption of the appliances of interest.

Secondly, limitations arise from the availability of appliance models, namely microwaves and ovens in our case. Indeed, the microwave model, proposed in Section 4.1. is limited by the availability of consumption data, and thus it is inadvertently biased towards the microwaves used in the study, which ranged between $700 \mathrm{~W}$ and $900 \mathrm{~W}$. Therefore, the accuracy of the model is expected to be lower for microwaves rated at greater than $1000 \mathrm{~W}$. Similarly, the oven model, proposed in Section 4.2 , is limited by the available ovens used in the study, that is, we expect that the model will not accurately represent very large ( $\geq 80$ litres) or very small ovens ( $\leq 50$ litres). At the time of the study, we endeavoured to include most commonly available microwave power ratings and oven volumes in the market. Models proposed in the study are validated on publicly available, recent (to reflect contemporary appliance ownership) UK, Swiss and USA smart meter datasets in Section 5 resulting in very good accuracy. The oven model is especially accurate when the duration of use is up to 45 minutes. 


\section{Application to food life cycle assessment}

In order to demonstrate the impact of accurate appliance models developed previously in food LCA applications, we provide a case study to assess the environmental impact of a frozen ready meal that is to be cooked at home. Results obtained are compared with the assessment reported by Schmidt Rivera et al. 32. In this section, unlike previous sections, the energy consumption variable $\left(E_{M W} \& E_{\text {Oven }}\right)$ is unknown and needs to be calculated, given the knowledge of all other variables, such as time duration, power rating and temperature settings.

\subsection{System set-up for the assessment of a frozen ready meal}

The goal of the assessment is to evaluate the environmental impact of one frozen ready meal consisting of chicken, vegetables (potato, peas and carrots) and tomato sauce, and cooked at home in the UK using a microwave oven or an electric oven, as directed by the cooking instructions printed in the packaging. The mass of the ready meal, as sold, is $360 \mathrm{~g}$. Figure 6 shows the scope of the assessment and the various life cycle stages taken into account, from agricultural production of ingredients, consumption, to end of life of packaging and food waste.

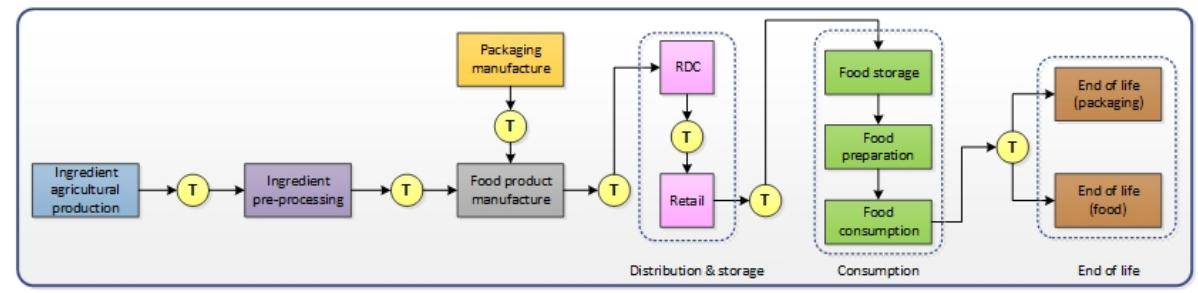

Figure 6: System boundaries in the life cycle assessment of a frozen ready meal. T: Transport; RDC: Retail Distribution Centre.

Transport of raw ingredients, processed ingredients, packaged ready meal and waste materials (food and packaging) are all included, accounting for ambient, refrigerated or frozen conditions as required, and the sourcing of materials 
(local, regional or imported). Primary, secondary and tertiary packaging of the ready meal is included. Food waste along the value chain as well as postconsumer waste is also taken into account.

In particular, cooking of the frozen ready meal is modelled as detailed in Table 5. for six scenarios considered in this assessment. The home cooking stage is modelled using three different sources of data: the appliance models proposed in the paper, the World Food LCA Database (WFLDB) 41, and the energy consumption models by a microwave oven and an electric oven developed by Jungbluth [12] and used in [32].

\begin{tabular}{|c|c|c|c|c|c|}
\hline Scenario & Appliance & Cooking Parameters & Appliance model & Energy Consumption [MJ] & Source \\
\hline 1 & Electric oven & $200^{\circ} \mathrm{C}$ for $40 \min$ & $0.183 \mathrm{MJ} / \min ($ Heat up + maintenance) & 7.32 & $12 \mid 32$ \\
\hline 2 & Electric oven & $200^{\circ} \mathrm{C}$ for $40 \mathrm{~min}$, Oven volume: 67 Litre & Eq. 6. & 3.65 & This paper \\
\hline 3 & Electric oven & $10 \mathrm{~min}$ preheat, $200^{\circ} \mathrm{C}$ for $40 \mathrm{~min}$ & Oven calculator of WFLDB (Heat up + maintenance) & $2.16+1.44=3.6$ & 41 \\
\hline 4 & Microwave oven & $9 \min$ & $0.0435 \mathrm{MJ} / \mathrm{min}$ & 1.41 & $12] 32$ \\
\hline 5 & Microwave oven & $800 \mathrm{~W}$ for $9 \mathrm{~min}$ & Eq. $[4]$ & 0.56 & This paper \\
\hline 6 & Microwave oven & $800 \mathrm{~W}$ for $9 \mathrm{~min}$ & $0.088 \mathrm{MJ} / \mathrm{min}$ (standby \& heating) & 0.79 & 41 \\
\hline
\end{tabular}

Table 5: Description of home cooking of one frozen ready meal. Six different scenarios are considered: 3 with electric oven and 3 with microwave.

The precise details of the inputs to the life cycle inventory of the study are detailed in 32] and were reproduced here (quantities, distances, cooking instructions, etc.). Background life cycle inventories (LCI), as shown in Table 6. are taken from publicly available databases: ecoinvent v.3.3 (SCLCI, 2016) and World Food LCA Database [41, and further detailed in [32]. The energy sources are regionalised for the elements considered key in this study, namely pre-processing of vegetables in the UK, manufacturing of ready meals in the UK, and use of the microwave oven in the UK. The other inputs contain electricity at either a European level or at global level. Two environmental impact indicators are evaluated: (1) greenhouse gas emissions 42 and (2) abiotic resource depletion - fossil fuels (CML, 2014) [43], which provide a suitable overview of the environmental impacts arising from energy consumption. The assessment was carried out using the specialised LCA software SimaPro, v. 8.3 [44]. 


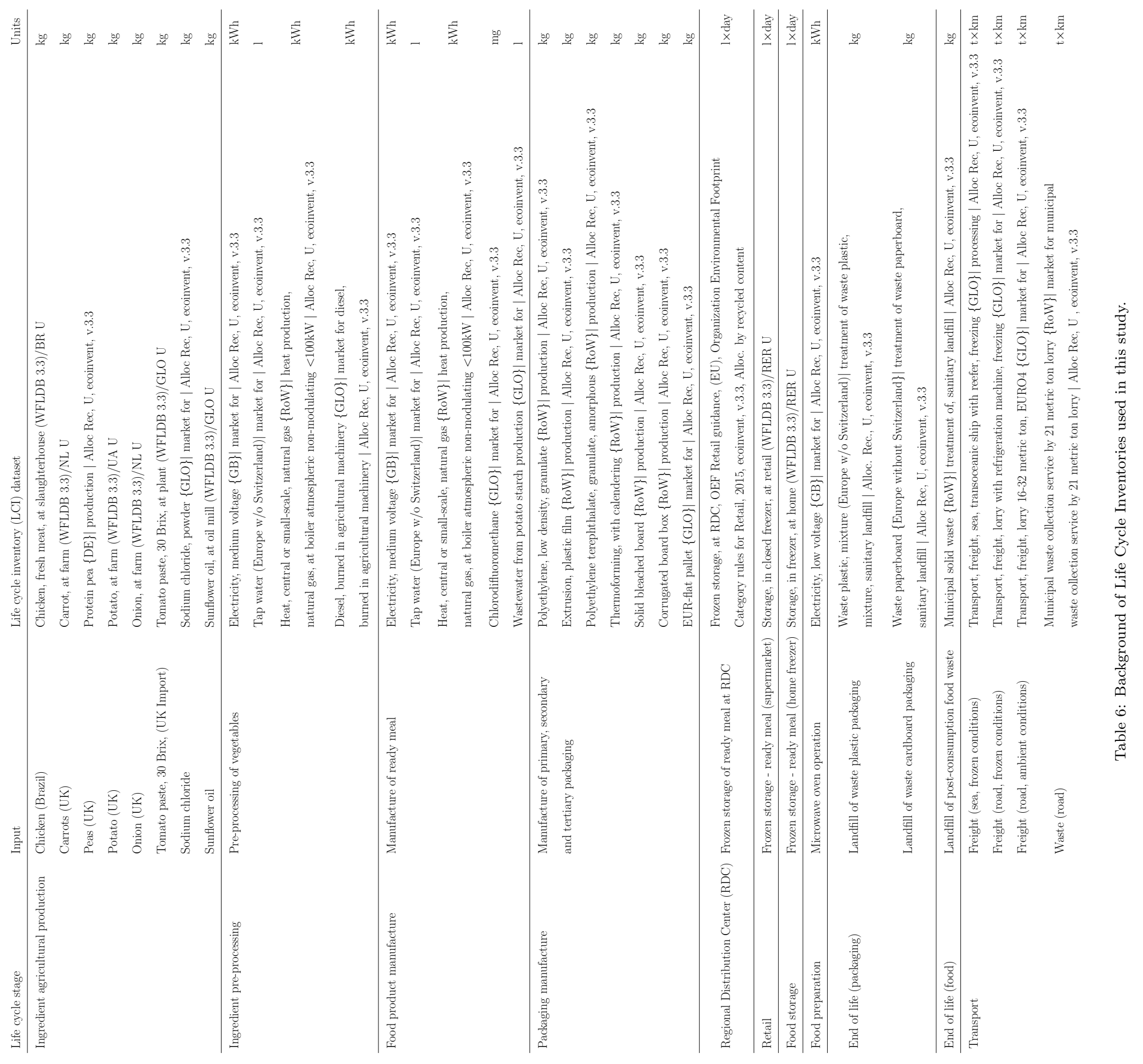




\subsection{Results}

Figs. 7 and 8 present the environmental impacts of the scenarios modelling the life cycle of the frozen ready meal. In turn, Tables 7 and 8 summarise the relative contributions of each life cycle stage to the overall results.

\begin{tabular}{lllllll} 
Life cycle stage & Scenario 1 & Scenario 2 & Scenario 3 & Scenario 4 & Scenario 5 & Scenario 6 \\
\hline Ingredients & $31.8 \%$ & $39.8 \%$ & $37.2 \%$ & $46.9 \%$ & $50.3 \%$ & $48.5 \%$ \\
Pre-Processing & $0.8 \%$ & $1.0 \%$ & $0.9 \%$ & $1.2 \%$ & $1.2 \%$ & $1.2 \%$ \\
Manufacture & $15.6 \%$ & $19.4 \%$ & $18.2 \%$ & $22.9 \%$ & $24.6 \%$ & $23.7 \%$ \\
Packaging & $5.2 \%$ & $6.4 \%$ & $6.0 \%$ & $7.6 \%$ & $8.2 \%$ & $7.9 \%$ \\
Distribution \& storage & $4.1 \%$ & $5.2 \%$ & $4.8 \%$ & $6.1 \%$ & $6.6 \%$ & $6.3 \%$ \\
Consumption & $39.8 \%$ & $24.8 \%$ & $29.6 \%$ & $11.3 \%$ & $4.8 \%$ & $8.2 \%$ \\
End of life (EOL) & $2.7 \%$ & $3.4 \%$ & $3.2 \%$ & $4.0 \%$ & $4.3 \%$ & $4.2 \%$
\end{tabular}

Table 7: Relative contribution of life cycle stages to overall results for greenhouse gas emissions.

\begin{tabular}{lllllll} 
Life cycle stage & Scenario 1 & Scenario 2 & Scenario 3 & Scenario 4 & Scenario 5 & Scenario 6 \\
\hline Ingredients & $16.8 \%$ & $22.1 \%$ & $20.7 \%$ & $27.3 \%$ & $30.0 \%$ & $28.8 \%$ \\
Pre-Processing & $1.1 \%$ & $1.4 \%$ & $1.3 \%$ & $1.7 \%$ & $1.9 \%$ & $1.8 \%$ \\
Manufacture & $19.1 \%$ & $25.1 \%$ & $23.5 \%$ & $31.0 \%$ & $34.1 \%$ & $32.6 \%$ \\
Packaging & $10.6 \%$ & $13.9 \%$ & $13.0 \%$ & $17.2 \%$ & $18.9 \%$ & $18.1 \%$ \\
Distribution \& storage & $4.4 \%$ & $5.8 \%$ & $5.5 \%$ & $7.2 \%$ & $7.9 \%$ & $7.6 \%$ \\
Consumption & $47.6 \%$ & $31.2 \%$ & $35.5 \%$ & $14.9 \%$ & $6.5 \%$ & $10.5 \%$ \\
End of life (EOL) & $0.3 \%$ & $0.5 \%$ & $0.4 \%$ & $0.6 \%$ & $0.6 \%$ & $0.6 \%$
\end{tabular}

Table 8: Relative contribution of life cycle stages to overall results for abiotic resource depletion - fossil fuels.

\subsubsection{Greenhouse gas (GHG) emissions}

The results, presented in Table 7 and Fig. 7, show that microwaving the frozen meal is associated with lower greenhouse gas emissions than cooking it in an electric oven, irrespective of the model used to represent the operation of the appliance. As can be seen from Fig. 7 (Consumption phase), Scenario 1, which uses the model of [12], shows results $14 \%$ to $20 \%$ higher $(3.4 \mathrm{~kg} \mathrm{CO}$-equivalent (eq) per frozen ready meal) than Scenarios 2 and 3, which use models proposed 
in this paper and the World Food LCA Database [41, respectively. This can be attributed to the fact that the latter models, especially the proposed model, represent more recent and more energy efficient oven technology. Similar results are observed for Scenarios 4 to 6 (2.1 $-2.3 \mathrm{~kg} \mathrm{CO}_{2}-$ eq per frozen ready meal), where microwaving is the cooking option.

The life cycle stage contributing the most to the overall results varies depending on the cooking method and the model used to represent the operation of the appliances. Except for Scenario 1 where the consumption stage is the largest contributor, in Scenarios 2 and 3 the consumption stage is the second contributor. Similarly, for microwaving scenarios - except for Scenario 4 where the consumption phase is the third largest contributor, in Scenarios 5 and 6 , the consumption stage using microwave is the 4th or 5th largest contributor.

\subsubsection{Abiotic resource depletion (ARD) - fossil fuels}

In the case of ARD - fossil fuels, the overall results, shown in Table 8 and Fig. 8, follow a pattern similar to the one observed for the GHG emissions. However, the stages contributing the most to the results follow a different order. Scenario 1 continues to show the highest results for the option of cooking with an electric oven (32.3 MJ per frozen ready meal); this is between 19\% and $24 \%$ higher than Scenarios 2 and 3. The option of microwaving, represented by Scenarios 4 to 6 , shows again similar results (18.1 MJ - 19.9 MJ). The largest contributor to the overall results for the option of cooking with an electric oven continues to be the consumption stage (ranging between $31 \%$ to $48 \%$ ), the second largest contributor is now the manufacturing stage (19\% to $25 \%$ ) and the ingredients stage comes in the third place (17\% to $22 \%$ ). When the microwaving option is assessed, it is the manufacturing stage which takes the first place (31\% to $34 \%$ ), whereas the ingredients stage is second (27\% to $30 \%$ ) and the packaging stage is third (17\% to $19 \%)$. These different rankings can be explained by the fact that this environmental impact indicator focuses on fossil fuels employed in the generation of electricity for the UK grid, fuel fed to boilers in the manufacturing plant, or as raw material in the production of packaging 
materials (plastic tray, plastic lid, shrinking film).

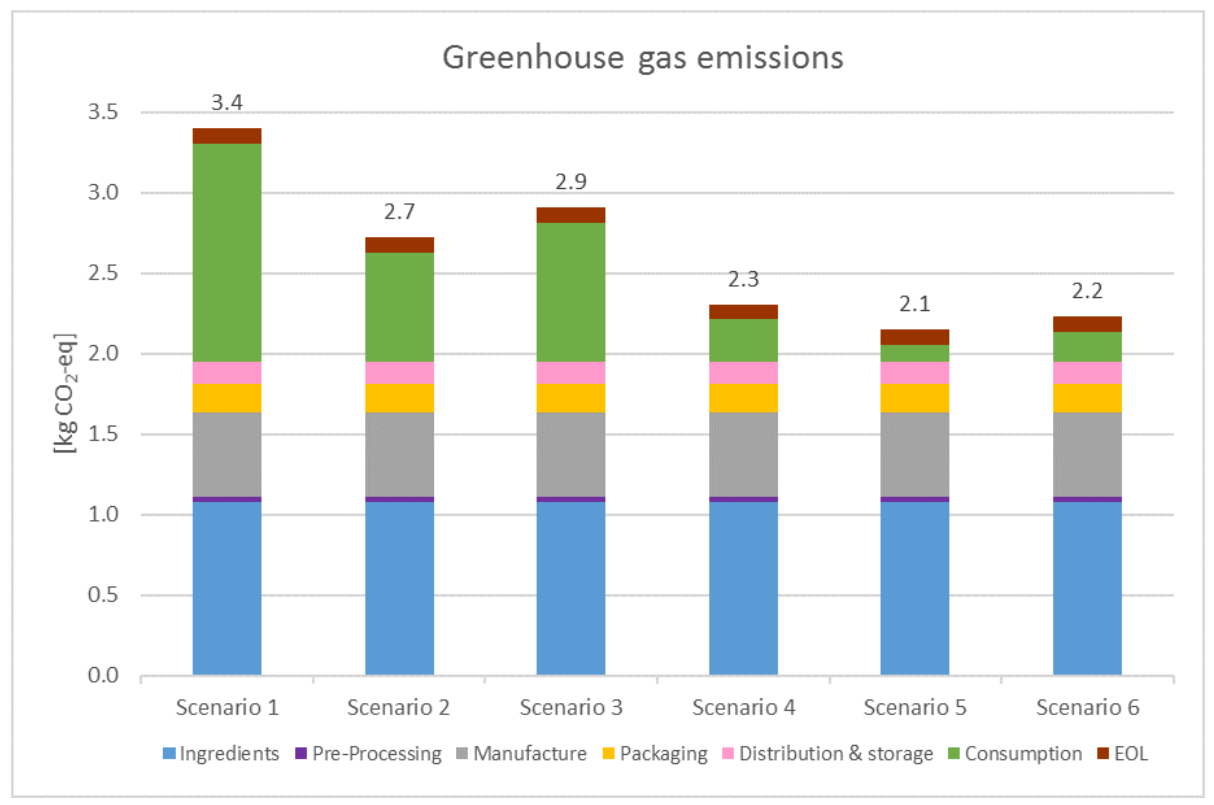

Figure 7: Greenhouse gas emissions associated with the life cycle of a frozen ready meal. Scenarios 1 to 3 model home cooking using an electric oven; Scenarios 4 to 6 model home cooking using a microwave oven. See Table 5 


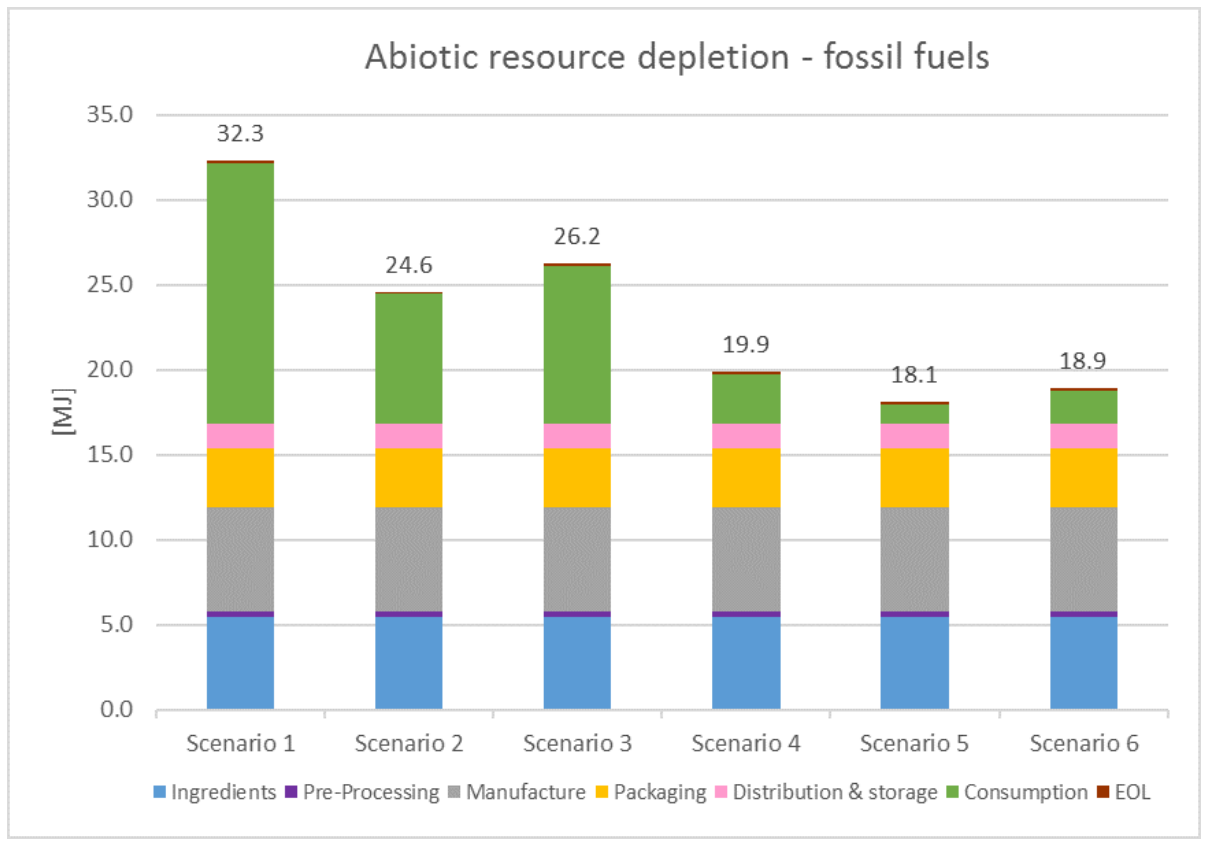

Figure 8: Abiotic resource depletion (ARD) - fossil fuels associated with the life cycle of a frozen ready meal. Scenarios 1 to 3 model home cooking using an electric oven; Scenarios 4 to 6 model home cooking using a microwave oven. See Table 5

\subsection{Validation of Results}

Table 9 compares our results to those of [32] and [41]. The difference in results can be explained twofold: a) the use of different life cycle inventory background databases by both studies, and b) the different models used to characterize the operation of microwave ovens and electric ovens. In particular, the higher energy consumption calculated using the model reported by Jungbluth [12] is representative of technology available at the time (at least 20 years old to date). Nevertheless, despite these differences, the results tend to fall into a close range, thus validating the purpose of this assessment: to obtain good quality results considering a minimum number of parameters to model home cooking of food products. 


\begin{tabular}{|c|c|c|c|c|c|}
\hline \multirow{2}{*}{ Scenario } & \multirow{2}{*}{ Cooking Method } & \multicolumn{2}{|c|}{$\begin{array}{c}\text { GHG emissions } \\
\text { (kg CO } \text {-eq }_{2} \text { frozen ready meal) }\end{array}$} & \multicolumn{2}{c|}{$\begin{array}{c}\text { Abiotic resource depletion } \\
\text { fossil fuels } \\
\text { (MJ/frozen ready meal) }\end{array}$} \\
\cline { 3 - 6 } & & Overall & $\begin{array}{c}\text { Consumption } \\
\text { Stage }\end{array}$ & Overall & $\begin{array}{c}\text { Consumption } \\
\text { Stage }\end{array}$ \\
\hline 1 & & 3.4 & 1.4 & 32.3 & 15.4 \\
2 & Electric & 2.7 & 0.7 & 24.6 & 7.7 \\
3 & Oven & 2.9 & 0.9 & 26.2 & 9.3 \\
RM-8 & & 3.6 & 1.4 & 34.0 & 19.7 \\
\hline 4 & & 2.3 & 0.3 & 19.9 & 3.0 \\
5 & Microwave & 2.3 & 0.3 & 19.9 & 3.0 \\
6 & Oven & 2.2 & 0.2 & 18.9 & 2.0 \\
RM-7 & & 2.4 & 0.2 & 17.7 & 2.7 \\
\hline
\end{tabular}

Table 9: Environmental impacts associated with a frozen ready meal. Comparison of results using the proposed model and the model of Schmidt Rivera et al. 32. RM-8 and RM-7 refer to two scenarios studied in 32 (see Table 15 in 32 ).

\section{Conclusion}

The conclusions drawn from validating our proposed models in large, geographically spread datasets, and demonstration in the Food LCA, confirm our hypothesis that by using only smart meter energy data, without resorting to other, difficult to obtain, parameters, such as food type, temperature, and weight, we can build accurate energy consumption models of major cooking appliances. In Section 4 the models for electric microwaves and ovens were generated from real consumption data, that implicitly incorporate user behaviour in usage of the appliances, contrary to relying on manufacturer's assumptions on how the appliances should be used and their resulting models. As user behaviour can impact the amount of energy an appliance consumes, by proposing a model which uses consumption data from (and is validated on) real homes (unlike previous studies which have used laboratory tests which do not take into account inefficient and unusual use cases), we show that, although human behaviour can cause variations at scale, it is possible to account for this via mathematical models generated from actual consumer usage data, which can be updated 
and scaled easily. In Section 5 we demonstrate that the proposed mathematical models are suitable to estimate appliance energy usage and are generally more accurate than previous models, reflecting recent trends in market availability and ownership of more efficient cooking appliances, and possibly more energyefficient approaches in cooking practices by households. As these trends will continue, it is necessary to have a scalable approach to large-scale food LCA as well as other large longitudinal consumer and energy studies, where information may be lacking with regards to specialised knowledge such as cooking settings, food temperature and weight, appliance makes and models. In Section 7, where the proposed models are compared with other state-of-the-art models used in the Consumption of Food LCA, we show that our models fall within a close range of contemporary energy efficient appliance technology consumption compared to non-scalable models proposed 20 years ago. Furthermore, we show that the Consumption phase of Food LCA is a significant contributor to greenhouse emissions and abiotic resource depletion. Therefore, the need arises to develop and update appliance consumption models on a regular basis and at relative low cost to reflect new technology. In turn, these models provide data that can satisfy LCA data quality requirements on time-related coverage, technology coverage, precision and representativeness.

The applicability of the proposed methodology for developing scalable appliance models from pervasive smart meter data embedding user behaviour is wide and goes beyond Food LCA. Indeed, from an energy-efficiency perspective, targeted energy feedback can be provided on consumers appliance usage habits and activities [29] leading to informed energy savings programmes and retrofit strategies for replacing appliances. Appliance manufacturers can get a better understanding of the actual consumption of appliances by customers and hence improve appliance design and life expectancy and consumption phase of appliance LCA. In relation to this, our study can augment consumer studies to identify habits and practices towards appliance repair and second-hand purchases, such as [45, and help meet targets within the waste policy framework. Furthermore, these models support environmental evaluation of appliances, thus 
enabling recommendations for the development of eco-design regulations in the EU, e.g., see [46.

\section{Acknowledgements}

This project was partly supported by Nestec S.A and carried out at the University of Strathclyde.

\section{Bibliography}

[1] B. Note, BNCK06 : Kettle trends (2006).

[2] G. Edwards-Jones, K. Plassmann, E. H. York, B. Hounsome, D. L. Jones, L. Milà i Canals, Vulnerability of exporting nations to the development of a carbon label in the United Kingdom, Environmental Science and Policy 12 (4) (2009) 479-490. doi:10.1016/j.envsci.2008.10.005.

[3] C. Thim, Domestic Appliances, in: H.-J. Bullinger (Ed.), Technology Guide, Principles ??? Applications ??? Trends, Springer US, 2009, pp. 458-461. doi:10.1007/978-3-540-88546-7.

[4] U. Sonesson, H. Janestad, B. Raaholt, Energy for Preparation and Storing of Food - Models for calculation of energy use for cooking and cold storage in households, no. 709, 2003.

[5] T. J. Hager, R. Morawicki, Energy consumption during cooking in the residential sector of developed nations: A review, Food Policy 40 (2013) 54-63. doi:10.1016/j.foodpol.2013.02.003.

URL http://dx.doi.org/10.1016/j.foodpol.2013.02.003

[6] C. E. Dutilh, K. J. Kramer, Energy Consumption in the Food Chain, AMBIO: A Journal of the Human Environmentdoi:10.1579/0044-7447-29. 2.98 
[7] A. D. Cuellar, M. E. Webber, An updated estimate for energy use in U.S. food production and policy implications, in: Proceedings of the ASME 4th International Conference on Energy Sustainability, Vol. 1, 2010, pp. 35-44. doi:10.1115/ES2010-90179

[8] M. C. Heller, G. Keoleian, Life cycle-based sustainability indicators for assessment of the U.S. food system, Report - Center for Sustainable Systems, School of Natural Resources and Environment, University of Michigan (CSS00-04) (2000) 59 pp.

[9] P. Bertoldi, B. Atanasiu, Electricity consumption and efficiency trends in the enlarged European Union - Status Report 2009, 2009.

[10] International Energy Agency, World Energy Outlook 2006, World Energy Outlookdoi:10.1787/weo-2006-en

URL http://books.google.com/books?hl=en $\{\&\}$ lr=\{\&\}id= JAcuHqDnI6gC $\{\&\} \circ i=$ fnd $\{\&\}$ pg=PA3 $\{\&\}$ dq=World+Energy+Outlook+ $2006\{\&\}$ ots $=$ NCadW-C961 $\{\&\}$ sig $=5$ wr - ct $\left\{\_\right\}$hWTzqi4Rlwo8G18L6Ax0

[11] D. K. De, N. M. Shawhatsu, N. N. De, M. I. Ajaeroh, Energy-efficient cooking methods, Energy Efficiency 6 (1) (2013) 163-175. doi:10.1007/ s12053-012-9173-7.

[12] N. Jungbluth, Life-Cycle-Assessment for Stoves and Ovens (1997) 1-52.

[13] S. Lakshmi, A. Chakkaravarthi, R. Subramanian, V. Singh, Energy consumption in microwave cooking of rice and its comparison with other domestic appliances, Journal of Food Engineering 78 (2) (2007) 715-722. doi:10.1016/j.jfoodeng.2005.11.011.

[14] T. Das, R. Subramanian, A. Chakkaravarthi, V. Singh, S. Z. Ali, P. K. Bordoloi, Energy conservation in domestic rice cooking, Journal of Food Engineering 75 (2) (2006) 156-166. doi:10.1016/j.jfoodeng.2005.04. 005. 
[15] J. Zufia, L. Arana, Life cycle assessment to eco-design food products: industrial cooked dish case study, Journal of Cleaner Production 16 (17) (2008) 1915-1921. doi:10.1016/j.jclepro.2008.01.010.

[16] L. A. Calderón, L. Iglesias, A. Laca, M. Herrero, M. Díaz, The utility of Life Cycle Assessment in the ready meal food industry, Resources, Conservation and Recycling 54 (12) (2010) 1196-1207. doi:10.1016/j.resconrec. 2010.03 .015

[17] L. A. Calderón, M. Herrero, A. Laca, M. Díaz, Environmental impact of a traditional cooked dish at four different manufacturing scales: from ready meal industry and catering company to traditional restaurant and homemade, International Journal of Life Cycle Assessment (2017) 113 doi:10.1007/s11367-017-1326-7.

[18] C. Oberascher, R. Stamminger, C. Pakula, Energy efficiency in daily food preparation, International Journal of Consumer Studies 35 (2) (2011) 201211. doi:10.1111/j.1470-6431.2010.00963.x.

[19] Vattenfall, Energiesparen macht Spaß und spart Geld, Tech. rep. (2008).

[20] G. Wood, M. Newborough, Dynamic energy-consumption indicators for domestic appliances: Environment, behaviour and design, Energy and Buildings 35 (8) (2003) 821-841. doi:10.1016/S0378-7788(02)00241-4.

[21] E. A. DeMerchant, User's Influence on Energy Consumption with Cooking Systems Using Electricity, Virginia Polytechnic Institute and State University (1997) 1-155.

URL http://hdl.handle.net/10919/29838

[22] R. Kemna, Energy Consumption of Domestic Appliances in European Households, Tech. rep. (2010).

[23] F. Burlon, Energy Efficiency of Combined Ovens, in: Energy Procedia, Vol. 82, Elsevier B.V., 2015, pp. 986-993. doi:10.1016/j.egypro.2015. 11.856 
[24] D. Papasidero, S. Pierucci, F. Manenti, Energy optimization of bread baking process undergoing quality constraints, Energy 116 (2016) 1-6. doi:10.1016/j.energy.2016.06.046.

URL http://dx.doi.org/10.1016/j.energy .2016.06.046

[25] A. Milani, C. Camarda, L. Savoldi, A simplified model for the electrical energy consumption of washing machines, Journal of Building Engineering 2 (2015) 69-76. doi:10.1016/j.jobe.2015.04.007.

URL http://dx.doi.org/10.1016/j.jobe.2015.04.007

[26] J. Geppert, Modelling of domestic refrigerators' energy consumption under real life conditions in Europe (2011) 145.

[27] P. Jason, I. Cooper, Smart metering implementation programme government response to the consultation on the second version of the smart metering equipment technical specifications part 1 (January) (2013) 14.

[28] D. Murray, J. Liao, L. Stankovic, V. Stankovic, Understanding usage patterns of electric kettle and energy saving potential, Applied Energy 171 (2016) 231-242. doi:10.1016/j . apenergy .2016.03.038.

URL http://www.sciencedirect.com/science/article/pii/ S0306261916303579

[29] L. Stankovic, V. Stankovic, J. Liao, C. Wilson, Measuring the energy intensity of domestic activities from smart meter data, Applied Energy 183 (2016) 1565-1580. doi:10.1016/j.apenergy.2016.09.087.

URL http://dx.doi.org/10.1016/j.apenergy .2016.09.087

[30] M. Pipattanasomporn, M. Kuzlu, S. Rahman, Y. Teklu, Load Profiles of Selected Major Household Appliances and Their Demand Response Opportunities 5 (2) (2014) 742-750.

[31] J. Riley, J. Hulme, Report 9: Domestic appliances, cooking \& cooling equipment, Tech. rep., BRE, Department of Energy and Climate Change (DECC) (2013). 
[32] X. C. Schmidt Rivera, N. Espinoza Orias, A. Azapagic, Life cycle environmental impacts of convenience food: Comparison of ready and homemade meals, Journal of Cleaner Production 73 (2014) (2014) 294-309. doi:10.1016/j.jclepro.2014.01.008. URL http://dx.doi.org/10.1016/j.jclepro.2014.01.008

[33] B. Zhao, L. Stankovic, V. Stankovic, On a Training-Less Solution for NonIntrusive Appliance Load Monitoring Using Graph Signal Processing, IEEE Access 4 (2016) 1784-1799. doi:10.1109/ACCESS.2016.2557460.

[34] J. Kelly, W. Knottenbelt, The UK-DALE dataset, domestic appliance-level electricity demand and whole-house demand from five UK homes., Scientific data 2 (2015) 150007. arXiv:1404.0284, doi:10.1038/sdata.2015.7. URL http://arxiv.org/abs/1404.0284

[35] D. Murray, L. Stankovic, V. Stankovic, An electrical load measurements dataset of United Kingdom households from a two-year longitudinal study 4463 (2016) 1-12. doi:10.1038/sdata.2016.122.

[36] C. Beckel, W. Kleiminger, R. Cicchetti, T. Staake, S. Santini, The ECO Data Set and the Performance of Non-Intrusive Load Monitoring Algorithms, Proceedings of the 1st ACM Conference on Embedded Systems for Energy-Efficient Buildings (2014) 80-89 doi:10.1145/2674061.2674064

[37] N. Batra, M. Gulati, A. Singh, M. B. Srivastava, It's Different: Insights into home energy consumption in India, Proceedings of the 5th ACM Workshop on Embedded Systems For Energy-Efficient Buildings BuildSys'13 (November) (2013) 1-8. doi:10.1145/2528282.2528293.

URL http://dl . acm.org/citation.cfm?doid=2528282.2528293

[38] K. He, L. Stankovic, J. Liao, V. Stankovic, Non-Intrusive Load Disaggregation using Graph Signal Processing, IEEE Transactions on Smart Grid 3053 (c) (2016) 1-1. doi:10.1109/TSG.2016.2598872.

URL http://ieeexplore.ieee.org/document/7539273/ 
[39] H. Altrabalsi, V. Stankovic, J. Liao, L. Stankovic, Low-complexity energy disaggregation using appliance load modelling, AIMS Energy 4 (1) (2016) 1-21. doi:10.3934/energy.2016.1.1.

[40] J. Z. Kolter, M. J. Johnson, REDD : A Public Data Set for Energy Disaggregation Research, SustKDD workshop xxxxx (1) (2011) 1-6. URL http://users.cis.fiu.edu/\{ \}lzhen001/activities/ KDD2011Program/workshops/WKS10/doc/SustKDD3.pdf

[41] X. Bengosa, T. Nemecek, V. Rossi, J. Lansche, S. Humbert, P. Mouron, World Food LCA Database (August).

[42] Intergovernmental Panel on Climate Change, Climate change 2013: The physical science basis, CLIMATE CHANGE 2013 - They Physical Science Basis.

[43] L. van Oers, CML-IA Characterisation Factors, Tech. rep. URL http://cml.leiden.edu/software/data-cmlia.html

[44] P. Sustainability, SimaPro Life Cycle Assessment software (2016).

[45] V. Pérez-Belis, M. Braulio-Gonzalo, P. Juan, M. D. Bovea, Consumer attitude towards the repair and the second-hand purchase of small household electrical and electronic equipment. A Spanish case study, Journal of Cleaner Production 158 (2017) 261-275. doi:10.1016/j.jclepro.2017. 04.143

[46] A. Gallego-Schmid, H. K. Jeswani, J. M. F. Mendoza, A. Azapagic, Life cycle environmental evaluation of kettles: Recommendations for the development of eco-design regulations in the European Union, Science of the Total Environment 625 (2018) 135-146. doi:10.1016/j.scitotenv . 2017. 12.262 ,

URL https://doi.org/10.1016/j.scitotenv.2017.12.262 